\title{
Endometrial adenocarcinoma in association with a levonorgestrel-releasing intrauterine system (Mirena ${ }^{\circledR}$ )
}

\author{
Franz M Ndumbe, Roy P Husemeyer
}

\begin{abstract}
Introduction
The levonorgestrel-releasing intrauterine system (LNGIUS), Mirena ${ }^{\circledR}$, has been licensed as a contraceptive in the UK since 1995. In 2002, Mirena became licensed also for the management of idiopathic menorrhagia and in 2004 the product licence was extended further to use for "endometrial protection" to prevent endometrial hyperplasia in women receiving oestrogen replacement therapy. We report a case of primary endometrioid endometrial carcinoma diagnosed in a postmenopausal woman who had a LNG-IUS inserted 4 years previously for treatment of perimenopausal menorrhagia, and we discuss the implications for management of women presenting with perimenopausal menorrhagia.
\end{abstract}

\section{Case report}

A 55-year-old multiparous woman presented with a history of intermittent vaginal bleeding, lower abdominal pain and weight loss. She had undergone laser ablation of a CIN 3 lesion of her cervix 12 years ago after which her cervical smears had remained negative. Four years previously she had complained of excessively heavy periods. Without prior endometrial biopsy she had an LNG-IUS inserted in a primary care setting for treatment of perimenopausal menorrhagia whereupon she became amenorrhoeic. She did not need the contraceptive effect of the intrauterine device as she had been sterilised following the birth of her third child.

She was also known to have Crohn's disease, diagnosed 7 years ago. For 3 months before presentation she had been experiencing abdominal pain and she had noticed weight loss of about $6 \mathrm{~kg}$, both of which she attributed to Crohn's disease. The principal reason for her seeking medical attention was the occurrence of intermittent vaginal bleeding for 2 months.

The patient weighed $60.5 \mathrm{~kg}$ and did not appear chronically ill. The findings on abdominal examination were unremarkable. The appearance of the cervix was normal and the uterus was not enlarged on bimanual palpation. The LNG-IUS was removed and an endometrial sampling device (Pipelle de Cornier ${ }^{\circledR}$, Laboratoire CCD, Paris, France) was used to obtain an endometrial biopsy. Ultrasonography showed a normal size uterus with endometrial thickness increased to $25 \mathrm{~mm}$ (normal $\leq 4 \mathrm{~mm}$ for a postmenopausal woman) and no adnexal abnormality. A chest X-ray was normal. Histology of the endometrial biopsy showed moderate to poorly differentiated (Grade 2 to 3 ) endometrial adenocarcinoma.

\section{J Fam Plann Reprod Health Care 2006; 32(2): 113-114}

(Accepted 25 November 2005)

United Lincolnshire Hospitals NHS Trust, Lincoln County Hospital, Lincoln, UK

Franz M Ndumbe, MB BS, MRCOG, Specialist Registrar in Obstetrics and Gynaecology

Roy P Husemeyer FFFP, FRCOG, Consultant Obstetrician and Gynaecologist

Correspondence to: Mr Roy P Husemeyer, Women and Children's Division, Lincoln County Hospital, Greetwell Road, Lincoln LN2 5QY, UK. E-mail: roy.husemeyer@ulh.nhs.uk
Surgical treatment was by total abdominal hysterectomy with bilateral salpingo-oophorectomy and pelvic lymphadenectomy. At the outset of the operation the peritoneal cavity was flushed with saline, which was then aspirated for cytological examination that proved negative for malignant cells. Histology revealed a moderately differentiated (Grade 2) endometrioid adenocarcinoma confined to the uterus with tumour invading the outer half of the myometrium but not extending to the peritoneal surface (FIGO Stage 1C).

\section{Discussion}

The LNG-IUS releases approximately $20 \mu \mathrm{g}$ levonorgestrel into the uterine cavity daily. This causes the endometrial glands to become inactive and the stroma to become decidualised. ${ }^{1}$ There is a reduction in the duration and the volume of menstrual blood loss over time. A reduction in menstrual blood loss of $94 \%$ was identified at 3 months in a randomised trial ${ }^{2}$ and up to $97 \%$ at 12 months in a noncomparative study. ${ }^{3}$

The LNG-IUS has been used to protect the endometrium from undergoing hyperplastic and neoplastic change in women using oestrogen replacement therapy 4 and it is now licensed for such use. The LNG-IUS has also been shown to have a protective action against the uterine effects of tamoxifen ${ }^{5}$ and it has been used effectively for primary treatment of early endometrial carcinoma. ${ }^{6}$ Therefore the LNG-IUS might reasonably be expected to protect women not being treated with oestrogen or tamoxifen against development of endometrial cancer. However, Jones et al. ${ }^{7}$ have reported the occurrence of endometrial carcinoma in two women following the insertion of a LNG-IUS. One of them, a 54-year-old multiparous woman, had an ultrasound scan and endometrial biopsy and then received cyclical combined oestrogen and progestogen hormone replacement therapy (HRT) for an unstated period of time before the LNG-IUS was inserted. It is open to speculation whether the HRT was implicated in the pathogenesis of adenocarcinoma following a negative endometrial biopsy. Alternatively, the biopsy may have yielded a false-negative result in the presence of an existing carcinoma low down in the uterine cavity, which was later rendered asymptomatic for a year by the insertion of the LNG-IUS.

The second case reported by Jones et al. ${ }^{7}$ was remarkably similar to the present case. A 48-year-old multiparous woman had presented with a 6-month history of irregular, heavy vaginal bleeding. A LNG-IUS had been inserted 3 years previously to treat menorrhagia, without prior endometrial sampling. The LNG-IUS was removed at hysteroscopy and curettage, which identified moderately differentiated invasive adenocarcinoma of the endometrium. In this case, as in the present case, the patient may already have had the carcinoma before the LNG-IUS was inserted, and without prior endometrial sampling it is impossible to know if this was indeed the case. If in these cases the malignancy antedated the insertion of the LNG-IUS then it is possible that the levonorgestrel released into the uterine cavity suppressed the symptoms of carcinoma. But Jones et al.'s case was found to have inoperable metastatic pelvic lymph nodes, and metastatic endometrial carcinoma would not be expected to be inhibited by the LNG-IUS.7 
These cases emphasise the importance of following the guidelines issued by the Faculty of Family Planning and Reproductive Health Care (FFPRHC) ${ }^{8}$ and the Royal College of Obstetricians and Gynaecologists (RCOG). 9,10 The RCOG evidence-based guideline on the initial management of menorrhagia ${ }^{9}$ does not identify the LNGIUS as a primary treatment option unless contraception is also required. The FFPRHC Clinical Effectiveness Unit (CEU) recommends that the LNG-IUS can be offered to women as a first-line treatment option for menorrhagia and supports the use of the LNG-IUS even if contraception is not required. ${ }^{8}$ The CEU asserts that endometrial assessment (biopsy or ultrasound scan) is not routinely required prior to LNG-IUS insertion for the management of menorrhagia. However, the caveat is added that women considering the LNG-IUS as a treatment for menorrhagia should be managed according to RCOG guidelines on the initial management of menorrhagia 9 and the management of menorrhagia in secondary care. ${ }^{10}$ Practitioners working in general practice or in family planning and reproductive health care are more likely to be familiar with FFPRHC than with RCOG guidance. Whereas the RCOG guideline on initial management ${ }^{9}$ does not recommend endometrial assessment by transvaginal ultrasound scan or endometrial biopsy, the guideline on management in secondary care ${ }^{10}$ states that the uterine cavity should initially be investigated by transvaginal ultrasound and that an endometrial biopsy should be considered for all women with persistent menorrhagia. The CEU Guidance ${ }^{8}$ emphasises that women who present with persistent menorrhagia, despite LNGIUS use, should be advised to return for further assessment of the uterine cavity (biopsy or ultrasound scan) to exclude pathology.

Carcinoma of the endometrium continues to be the most common gynaecological malignancy affecting Western women. ${ }^{11}$ Although relatively rare before the age of 40 years, the age-specific incidence increases steeply after the age of 44 years but then remains more or less static from age 55 years onwards. ${ }^{11}$ We conclude that the present case and the two previously reported cases of endometrial carcinoma in association with a LNG-IUS provide compelling grounds for routine endometrial assessment by ultrasound and biopsy before insertion of a LNG-IUS for treatment of menorrhagia in perimenopausal women and for the thorough investigation of women in this age group who develop abnormal bleeding with a LNG-IUS in place.

Statements on funding and competing interests

Funding. None identified.

Competing interests. None identified.

References

1 Silverberg SG, Haukkamaa K, Arko H. Endometrial morphology during long-term use of the levonorgestrel-releasing intrauterine device. Int J Gynecol Pathol 1986; 5: 235-241.

2 Irvine GA, Campbell-Brown MB, Lumsden MA, Heikkila A, Walker JJ, Cameron IT. Randomised comparative trial of the levonorgestrel intrauterine system and norethisterone for treatment of idiopathic menorrhagia. Br J Obstet Gynaecol 1998; 105: 592-598.

3 Andersson JK, Rybo G. Levonorgestrel-releasing intrauterine device in the treatment of menorrhagia. Br J Obstet Gynaecol 1990; 97: 690-694.

4 Riphagen F. Intrauterine application of progestins in hormone replacement therapy: a review. Climacteric 2000; 3: 199-211.

5 Gardner FJ, Konje JC, Abrams KR, Brown LJ, Khanna S, Al-Azzawi $\mathrm{F}$, et al. Endometrial protection from tamoxifen-stimulated changes by a levonorgestrel-releasing intrauterine system: a randomised controlled trial. Lancet 2000; 356: 1711-1717.

6 Giannopoulos T, Butler-Manuel S, Tailor A. Levonorgestrelreleasing intrauterine system (LNG-IUS) as a therapy for endometrial carcinoma. Gynecol Oncol 2004; 95: 762-764.

7 Jones K, Georgiou M, Hyatt D, Spencer T, Thomas H. Endometrial adenocarcinoma following the insertion of a Mirena IUCD. Gynecol Oncol 2002; 87: 216-218.

8 Faculty of Family Planning and Reproductive Health Care Clinical Effectiveness Unit. FFPRHC Guidance (April 2004). The levonorgestrel-releasing intrauterine system (LNG-IUS) in contraception and reproductive health. J Fam Plann Reprod Health Care 2004; 30: 99-109.

9 Royal College of Obstetricians and Gynaecologists (RCOG). The Initial Management of Menorrhagia (National Evidence-Based Guidelines). London, UK: RCOG Press, 1998.

10 Royal College of Obstetricians and Gynaecologists (RCOG). The Management of Menorrhagia in Secondary Care (National EvidenceBased Guidelines). London, UK: RCOG Press, 1999.

11 Quinn M, Jones B, Dina R, Soutter P. Malignant disease of the uterus. In: Shaw RW, Soutter WP, Stanton SL (eds), Gynaecology (3rd edn). London, UK: Churchill Livingstone, 2003; 632-648.

\section{HOW TO REGISTER FOR ACCESS TO THE ELECTRONIC JOURNAL}

\section{Registration Process}

1. On connecting with the Faculty website (www.ffprhc.org.uk), click on the picture of the 'Journal' to access the electronic Journal.

2. Next, under Related Links, click on 'Faculty Membership Activation'.

3. In the appropriate boxes enter your Surname, E-mail Address, Country and Membership Number (M000, D000, etc - six digits). NB. These boxes are case-sensitive.

4. Next, select a User Name and Password.

5. Ignore the box marked 'Ingenta Select ID number - CID'.

6. Click on 'Enable Access'.

7. A confirmation e-mail will be sent to you.

\section{After Registration}

Once you have registered you can access the Journal as follows:

1. On connecting with the Faculty website (www.ffprhc.org.uk), click on the picture of the 'Journal' to access the electronic Journal.

2. Select the volume and issue number.

3. Select the article you wish to view.

4. Enter your user name and password. 